\title{
Leituras em constelação: literatura traduzida e história literaria
}

Karina de Castilhos LuCEna (2020).

Porto Alegre: Bestiário, 188 páginas.

ISBN 978-65-991765-3-1

\section{- Lucía Belmes}

Instituto de Literatura Hispanoamericana, Universidad de Buenos Aires, Argentina

lubelmes@gmail.com

Leituras em constelação: literatura traduzida e história literária, de Karina de Castilhos Lucena, reúne ensayos que se articulan a partir de interrogantes sobre la traducción y su relación con la tradición y la historia literaria. Las ideas desplegadas son, según introduce la autora, fruto de estudios enmarcados en su actividad docente en la Universidade Federal do Rio Grande do Sul (UFRGS) y en instancias de investigación en el Programa de Posgrado en Estudios de Traducción de la Universidade Federal de Santa Catarina (PGET-UFSC). Los ensayos que conforman el libro proponen intersecciones teórico-críticas necesarias, que actualizan los debates contemporáneos en torno a la traducción.

El libro está estructurado en tres partes, la primera de ellas, "Tradução e Tradição", tiene como punto de partida una lectura de obras fundamentales de Walter Benjamin, Sobre el concepto de historia, La tarea del traductor, La tarea del crítico, deteniéndose en ciertos aspectos de las traducciones de estas obras al portugués. Lucena toma las ambivalencias, variaciones y revisiones en las traducciones alrededor el concepto de tarefa-renúncia como un aspecto clave en los ensayos de Benjamin, en articulación con los estudios sobre historia de la traducción e historia de la literatura. Desde este inicio propone una forma benjaminiana de concebir la historia, la tarea crítica y la traducción. Esta perspectiva particular se introduce en los primeros ensayos y estará presente en los siguientes, de maneras más o menos explícitas. Es central esta presentación y el recorrido que Lucena traza en la primera parte porque permite vislumbrar el ejercicio que la autora propondrá a lo largo del libro. A través de la puesta en diálogo de distintas obras, distintas posturas teóricas, consigue revelar zonas desde las cuales esa interacción sobre los textos ilumina nuevas lecturas. En esta línea, presenta una metodología de lectura e interpretación que quiebra la linealidad para sumergirse en un campo de tensiones.
En el ensayo "Antonio Candido, Roberto Schwarz e Haroldo de Campos: leituras em constelação", desarrolla su análisis proponiendo una filiación benjaminiana entre los críticos brasileños. La lectura propone un riesgo, un diálogo que no busca asimilar distintas posturas sino exhibir zonas de contacto desde las cuales es posible una reflexión sobre la recepción e influencias de obras traducidas, sobre la literatura nacional, entre otros. En "A obra-prima de uma tradutora: o Popol Vuh de Josely Vianna Baptista” destaca el lugar de la traductora también como autora del texto y describe el trabajo filológico de la poeta Josely Vianna Baptista en la elaboración de su versión del Popol Vuh traducido al portugués. Con este caso, Lucena va ilustrando otros en los cuales la traducción funciona como una intervención sobre el texto, y también sobre el campo literario y el horizonte de circulación. Desde allí, avanza reuniendo las figuras de Itamar Even-Zohar, Ricardo Piglia y Franco Moretti en "A tradução como potência para a tradição literária”, destacando el lugar que otorgan a la traducción de obras extranjeras y el impacto de esto en la formación de las tradiciones literarias locales. Toma el caso de Roberto Arlt y Juan Carlos Onetti como dos escritores para quienes el acceso a obras extranjeras traducidas jugó un papel central en el desarrollo de su formación intelectual, y en cuyas obras se pueden leer rastros y alusiones a estas traducciones. A través del estudio de estas figuras literarias emblemáticas para la literatura rioplatense del siglo XX, el ensayo trabaja también en la especificidad de la relación entre traducción y distinción social (nuevamente, leyendo en ese cruce un campo de tensiones).

La segunda parte, "Brasileiros traduzidos", contempla dos ensayos sobre la recepción de autores brasileños en el extranjero. En "Escritores gaúchos traduzidos: levantamento e comentario" estudia la recepción de los principales escritores de Rio Grande do Sul. Ilustra, con datos estadísticos, el desarrollo de las traducciones de dichos escritores a diferentes lenguas y analiza la figura de Erico Verissimo como 
el autor brasileño que más publicaciones ha tenido en lenguas extranjeras. Este ensayo da lugar a una reflexión respecto de la relación entre las lenguas española y portuguesa, en tanto los datos que Lucena va recuperando dan cuenta de la importancia de la traducción al español para la difusión internacional de escritores brasileños. A partir de eso, retoma la figura de Ángel Rama -sobre la cual trabaja principalmente en la primera parte- para plantear la vigencia de la comarca pampeana, que aproxima las regiones de Rio Grande do Sul y el Río de la Plata, y enfatiza en la potencia que existe en ese contacto entre las periferias. En el segundo ensayo, se focaliza en el caso de Machado de Assís y estudia la recepción y difusión hispanoamericana del autor, prestando especial atención a la inclusión de las obras de Machado en cierto canon literario argentino.

En la última parte del libro, "Literatura hispano-americana e literatura brasileira: paralelos", desarrolla una lectura comparativa a partir de determinadas obras de la literatura brasileña e hispanoamericana. En el ensayo "Julio Cortázar e Clarice Lispector: pontos de junção e disjunção", Lucena traza un análisis reflexionando sobre ciertas aristas comunes entre ambas figuras -recorriendo aspectos de sus biografías y sus producciones literarias $-y$, desde ese cruce, revela nuevos sentidos en la lectura de obras consagradas de la literatura latinoamericana. En "Literatura chilena e redemocratização: anotações sobre A morte e a donzela, de Ariel Dorfman, e Jamais o fogo nunca, de Diamela Eltit" desarrolla un análisis de las novelas que se centra en la experiencia chilena de la transición democrática. El libro cierra con dos ensayos sobre el escritor brasileño Julián Fuks en los cuales propone una lectura de la novela $A$ resistência, y su relación filial con la Argentina. A través de estos ensayos, se elaboran nuevos interrogantes y miradas respecto a la articulación entre traducción y tradición literaria, trabajando desde cruces geográficos que traspasan los límites de lo nacional para pensar en una perspectiva latinoamericana, que contempla la singularidad de cada territorio y cada literatura nacional, pero que atiende también a la potencia de esas constelaciones posibles. 